\title{
Intraoperative intraocular pressure fluctuation during standard phacoemulsification in real human patients
}

\author{
Libor Hejsek', Jana Kadlecovaa ${ }^{a}$, Martin Sin ${ }^{\mathrm{b}}$, Vera Velika ${ }^{\mathrm{a}}$, Nada Jiraskova ${ }^{\mathrm{a}}$
}

\begin{abstract}
Introduction. To evaluate the results of the fluctuations of intraocular pressure (IOP) and calculated mean ocular perfusion pressure (MOPP) during the usual steps of standard phacoemulsification.

Methods. Nine human eyes were evaluated. The IOP was measured indirectly by electronic applanation tonometer. The MOPP was calculated using the systolic blood pressure (SBP), the diastolic blood pressure (DBP) and the IOP: MOPP $=2 / 3 x[D B P+1 / 3 x(S B P-D B P)]-I O P$. The operations were performed with the INFINITI ${ }^{\prime} V$ ision System: main incision $2.2 \mathrm{~mm}$, coaxial handpiece, 2 paracenteses $1.1 \mathrm{~mm}$, bimanual irrigation/aspiration, bottle height $100 \mathrm{~cm}$. As ocular viscoelastic device (OVD) Hypromel 2.5\% (UNIMED) was used.

Results. The initial and final IOPs were 17-30 Torr (median 18) and 6-16 Torr (median 8), respectively. The IOP values oscillated between 4 and 63 Torr during the procedure. The highest values of the IOP were achieved at the beginning of phacoemulsification (from 42 to 63 Torr). The maximum pressure higher than $50 \mathrm{mmHg}$ and $60 \mathrm{mmHg}$ was found in $89 \%$ and $30 \%$ of cases, respectively. The mean ocular perfusion pressure (MOPP) at the beginning of the procedure was 46.4-67.0 (median 53.3) and 0.4-42.0 (median 19.3) during the maximum intraocular pressure.

Conclusions. Measured IOP as well as MOPP varied in all normal steps of real phacoemulsification. High values of intraoperative $\mathrm{IOL}$ induced by irrigation may compromise the intraocular perfusion. These fluctuations may induce impairment of the optic nerve perfusion, as well as retina, or choroid.
\end{abstract}

Key words: intraocular pressure, intraoperative IOP, phacoemulsification, perfusion

Received: June 26, 2018; Accepted: October 12, 2018; Available online: November 6, 2018 https://doi.org/10.5507/bp.2018.065

${ }^{a}$ Eye Clinic, University Hospital and Charles Medical Faculty, Hradec Kralove 500 05, Czech Republic ${ }^{b}$ Department of Opthalmology, University Hospital Olomouc, Czech Republic Corresponding author: Libor Hejsek, e-mail: libor.hejsek@gmail.com

\section{INTRODUCTION}

Phacoemulsification was introduced by Kelman in 1967 (ref. $^{1}$ ). Since that time, there has been significant development of this technique. At present, phacoemulsification is the most frequently performed ophthalmic surgical procedure in human ophthalmology. With the ongoing development of the cataract surgery, cataract surgeons tend to use high vacuum to do the surgery quickly. The increased vacuum may bring the unstable anterior chamber. To ensure anterior chamber stability during the procedure, higher infusion height is needed, inducing the intraocular pressure (IOP) elevation.

The perioperative intraocular tension is given by the initial eye tension, factors of irrigation (especially the height of the bottle of the phacoemulsification machine - a type without active fluidics), factors of aspiration (suction parameters), and tightness of the surgical wounds. Fluidics affects stability of the anterior chamber, and is a precondition for the efficacy of a phacoemulsification substance. High perioperative pressure is a factor in potential damage to the corneal endothelium or its postoperative oedema as well as a factor affecting flow in the eye vessels.

The fluid pressure (in Torr, millimetres of mercury) at the base of a column of water is derived as: pressure
$(\mathrm{mmHg})=$ column height $(\mathrm{cm}) \times 10 / 13.6$, when the density of mercury is $13.6 \mathrm{~g} / \mathrm{cm}^{3}$ and the density of water is $1 \mathrm{~g} / \mathrm{cm}^{3}$ (ref. ${ }^{2}$ ).

In the eye, the vascular pressure begins in the arteries and ends with the venous pressures in the ending stream. The pressure resistance is given by the blood elements and the vessel length, by branching and by the vascular diameter. The pressure decreases from the arteries to the capillaries, and the main source of resistance lies in the small arteries and arterioles. The intraocular veins work as a "Starling resistors": their pressure, before the outflow from the eye, must be higher than the IOP or the flow stops $^{3-5}$. Therefore, the IOP significantly influences the intraocular vascular flow.

Under normal circumstances, the mean arterial pressure (MAP) can be estimated using the systolic blood pressure (SBP) and diastolic blood pressure (DBP). Then, $\mathrm{MAP} \approx \mathrm{DBP}+1 / 3(\mathrm{SBP}-\mathrm{DBP})$. The mean ocular perfusion pressure (MOPP) is calculated as MOPP $=2 / 3$ MAP - IOP (ref. ${ }^{6}$ ). Perfusion pressure is important for maintaining the ocular blood flow?

Clinical example: A patient with SBP of $120 \mathrm{mmHg}$ and DBP of $70 \mathrm{mmHg}$ has IOP of $20 \mathrm{mmHg}$. Then MAP $\approx 87 \mathrm{mmHg}$ and his/her MOPP $\approx 38 \mathrm{mmHg}$. Surgery starts, and the level of infusion is $100 \mathrm{~cm}$, which induces $74 \mathrm{mmHg}$ pressure in the irrigating line. If there is 
no function of aspiration (or leakage through surgical wounds), this pressure is higher than the arterial input pressure (MOPP $\approx-16$ ), so the ocular flow will stop completely during this part of surgery.

Several papers were published to evaluate the visual loss by transient increase of IOP ( ref. $\left.^{8}\right)$. Findl et al. published that the IOP increase by a $20 \mathrm{mmHg}$ lasting $5 \mathrm{~min}$ reduced vascular flow in the optic nerve, retina, and choroid in healthy eyes ${ }^{9}$. Acute IOP increase even for less than 60 seconds may stifle the transport of neurotrophins from the brain to the retina ${ }^{10}$. Moreover, the relationship between the IOP during phacoemulsification and the subsequent non-arteritic anterior ischaemic optic neuropathy (NAION) was assumed ${ }^{11}$. Fluctuations in the IOP and its acute elevation may induce compression of the nerve fibres in primary glaucoma eyes, and may hence cause damage to the remains of the visual field ${ }^{12}$.

These publications suggested the risk of transient IOP elevations on retinal and optic nerve vessels and for impairment of visual function.

The aim of the study is to evaluate the values of the intraocular pressure during the basic phases of standard cataract surgery using phacoemulsification. As far as we have been able to determine, no study evaluating the fluctuation of the intraocular pressure during standard cataract surgery in real patients has yet been published.

\section{METHODS}

All measurements were carried out during all basic phases of real standard cataract surgery of the human eye of a living patient without using an animal or cadaver model. All surgeries were performed in local (Benoxi gtt., Tetracain gtt.) and intracameral (Lidocaine) anaesthesia by one surgeon (L.H.) and the intraoperative IOP measurements were performed by his assistant (J.K.). All procedures were performed using the microsurgical unit (without active fluidics) INFINITI ${ }^{\circledR}$ Vision System (Alcon Laboratories, Inc., Fort Worth, TX): the main incision of $2.2 \mathrm{~mm}$, coaxial handpiece, two service paracenteses of $1.1 \mathrm{~mm}$, bimanual irrigation/aspiration, the height of the bottle was $100 \mathrm{~cm}$. Hypromel 2.5\% (UNIMED) was a common OVD, and the quick-chop phacoemulsification technique was generally used.

The group consisted of nine patients, median age was 81 years. There were seven females and two males. One of the patients had pseudoexfoliative glaucoma, one had primary glaucoma with a closed angle and the other patients had no clinically significant eye pathologies. All these patients signed informed consent forms for the procedure, and all were treated in accordance with the tenets of the Declaration of Helsinki.

Immediately before surgery, routine blood pressure measurement was done on the right arm using the digital tonometer.

The IOP measurement was performed in a supine position following draping and application of the spreader. The intraocular tension was measured using the sterile contact end of the electronic applanation tonometer Tono-Pen XL (Reichert/Medtronic). The intraocular pressure was measured in each patient: prior to surgery, following filling of the anterior chamber (AC) with OVD, following capsulorhexis (CCC), following hydrodissection, at the beginning of phacoemulsification of the lens, during phacoemulsification of the lens, at the end of phacoemulsification (in the "epinucleus" regimen), during irrigation/aspiration (I/A), prior to implantation of the intraocular lens (IOL), during implantation of the intraocular lens, during lavage of the OVD and at the end of surgery (Table 1).

\section{RESULTS}

Contact measurements of the intraocular tension did not cause complications on the surface of the cornea, did not jeopardise mechanical safety of the procedure and no intraocular infectious complication was found during the postoperative procedure.

The initial and last IOPs were 17-30 Torr (median 18) and 6-16 Torr (median 8), respectively. The IOP values oscillated between 4 and 63 Torr during the procedure. The intraocular pressure following filling the AC with OVD, following CCC ( 8 Torr), following hydrodissection (10 Torr) and during rinsing of the visco material (14 Torr) was lower compared with that at the beginning of surgery (median 15 Torr). On the contrary, we measured an increase of the intraocular tension at the beginning of phacoemulsification (median 54 Torr), during phacoemulsification (26 Torr), at the end of phacoemulsification (36 Torr) and during irrigation/aspiration of the cortical masses (20 Torr). The highest values of the IOP were achieved at the beginning of phacoemulsification (from 42 to 63 Torr) (Fig. 1). Maximum pressure of higher than $40 \mathrm{mmHg}$ was measured in $100 \%$ of the cases, higher than $50 \mathrm{mmHg}$ in $89 \%$ of the cases, and higher than $60 \mathrm{mmHg}$ in $30 \%$ of the cases.

Prior to and during implantation of the intraocular lens, the IOP was 18 Torr (median).

The systolic blood pressure of the patients ranged from 130 to $180 \mathrm{mmHg}$ (median 158), and the diastolic blood pressure ranged from 73 to $100 \mathrm{mmHg}$ (median 93). The mean ocular perfusion pressure (MOPP) at the beginning of the procedure was 46.4-67.0 (median 53.3), and 0.4-42.0 (median 19.3) during maximum intraocular tension.

Table 2 shows the blood pressure values prior to surgery and calculation of eye perfusion using the MOPP.

\section{DISCUSSION}

As far as we have been able to determine, no study evaluating the fluctuation of the intraocular pressure during standard cataract surgery in real patients has yet been published. Simulated measurements in real eyes were performed by Zhao et al. ${ }^{8}$ and in cadaver eyes by Khng 
Table 1. IOP measured in all ususal steps of phacoemulsification.

\begin{tabular}{|c|c|c|c|c|c|c|c|c|c|c|c|c|c|c|}
\hline $\mathrm{n}$ & $\begin{array}{c}\text { age } \\
\text { (years) }\end{array}$ & history & 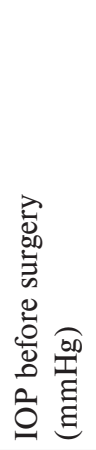 & 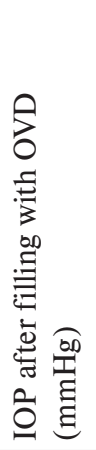 & 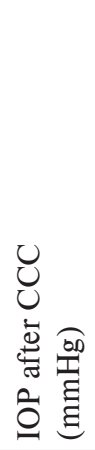 & 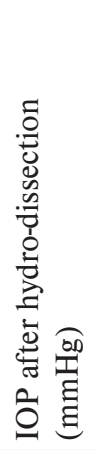 & 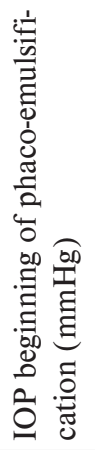 & 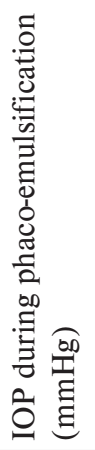 & 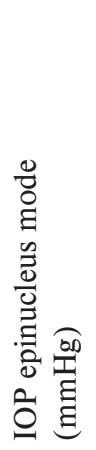 & 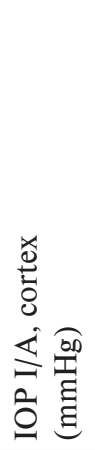 & 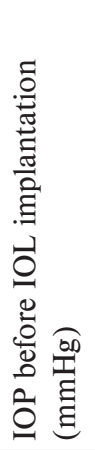 & 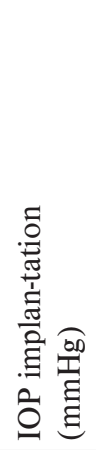 & 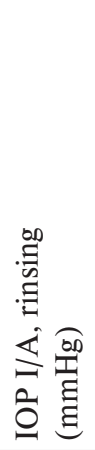 & 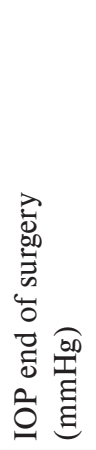 \\
\hline 1 & 85 & DM 2 & 17 & 15 & 8 & 6 & 58 & 28 & 36 & 32 & 14 & 14 & 13 & 15 \\
\hline 2 & 85 & & 16 & 7 & 7 & 10 & 50 & 26 & 43 & 7 & 10 & 19 & 10 & 8 \\
\hline 3 & 87 & $\begin{array}{l}\text { pseudo-exf. } \\
\text { glaucoma }\end{array}$ & 30 & 31 & 6 & 8 & 51 & 40 & 30 & 20 & 18 & 10 & 15 & 8 \\
\hline 4 & 70 & & 20 & 8 & 8 & 14 & 63 & 29 & 36 & 18 & 14 & 51 & 24 & 6 \\
\hline 5 & 81 & PCAG & 18 & 23 & 16 & 23 & 62 & 16 & 15 & 17 & 14 & 11 & 20 & 8 \\
\hline 6 & 71 & & 18 & 16 & 14 & 16 & 58 & 24 & 46 & 64 & 18 & 14 & 27 & 6 \\
\hline 7 & 68 & & 28 & 4 & 10 & 35 & 51 & 14 & 26 & 37 & 20 & 18 & 14 & 16 \\
\hline 8 & 85 & DM 2 & 18 & 58 & 20 & 4 & 54 & 21 & 55 & 20 & 18 & 31 & 10 & 12 \\
\hline 9 & 73 & & 17 & 5 & 8 & 10 & 42 & 35 & 36 & 29 & 20 & 18 & 14 & 6 \\
\hline median & 81.0 & & 18.0 & 15.0 & 8.0 & 10.0 & 54.0 & 26.0 & 36.0 & 20.0 & 18.0 & 18.0 & 14.0 & 8.0 \\
\hline
\end{tabular}

(OVD - Ophthalmic Viscosurgical Device, CCC - continuous curvilinear capsulorhexis, I/A - irrigation/aspiration, IOL - intraocular lens)

Table 2. Blood pressure values prior to surgery and calculation of eye perfusion.

\begin{tabular}{cccccccc}
\hline $\mathrm{n}$ & $\begin{array}{c}\text { age } \\
(\text { years })\end{array}$ & $\begin{array}{c}\mathrm{SBP} \\
(\mathrm{mmHg})\end{array}$ & $\begin{array}{c}\mathrm{DBP} \\
(\mathrm{mmHg})\end{array}$ & $\begin{array}{c}\text { IOP } \\
\text { (before } \\
\text { surgery) } \\
(\mathrm{mmHg})\end{array}$ & $\begin{array}{c}\text { MOPP } \\
(\text { starting IOP) } \\
(\mathrm{mmHg})\end{array}$ & $\begin{array}{c}\text { IOP (maximal } \\
\text { during } \\
\text { surgery) } \\
(\mathrm{mmHg})\end{array}$ & $\begin{array}{c}\text { MOPP } \\
(\mathrm{max} . \mathrm{IOP}) \\
(\mathrm{mmHg})\end{array}$ \\
\hline 1 & 85 & 148 & 100 & 17 & 60.3 & 58 & 19.3 \\
2 & 85 & 149 & 73 & 16 & 49.6 & 50 & 15.6 \\
3 & 87 & 165 & 95 & 30 & 48.9 & 51 & 27.9 \\
4 & 70 & 160 & 85 & 20 & 53.3 & 63 & 10.3 \\
5 & 81 & 150 & 90 & 18 & 55.3 & 62 & 11.3 \\
6 & 71 & 130 & 80 & 18 & 46.4 & 64 & 0.4 \\
7 & 68 & 158 & 93 & 28 & 48.4 & 51 & 25.4 \\
9 & 85 & 170 & 100 & 18 & 64.2 & 54 & 28.2 \\
9 & 73 & 180 & 99 & 17 & 67.0 & 42 & 42.0 \\
\hline
\end{tabular}

(SBP - systolic blood pressure, DBP - diastolic blood pressure, IOP - intraocular pressure, MOPP - mean ocular perfusion pressure)

et al. ${ }^{2}$ In the first work, the authors measured IOP under simulated conditions without active phacoemulsification. In the second work the intraocular tension parameters were evaluated on 4 cadavers eyes, measured by pressure transducer placed in the vitreous cavity, and it is unclear how much the model approaches real clinical conditions.

In our group of patients, the IOP values during surgery fluctuate, but most often they achieve the highest values during the phacoemulsification procedure. Machineinduced short-term intraocular hypertension without active fluidics reduced the mean ocular perfusion pressure almost threefold. In one case (11\%), the MOPP was practically zero, i.e. theoretically closing blood flow in the eye vessels. The highest IOP values are typically achieved at the beginning of phacoemulsification when the anterior chamber is filled with OVD and at the same time pressurised by water pressure from the phacoemulsification probe. The time period of transient intraocular hypertension in uncomplicated cataract surgery occurs several times in succession, lasts for seconds to tens of seconds, and is reversible.

Very high IOP values were also recorded by the probe 


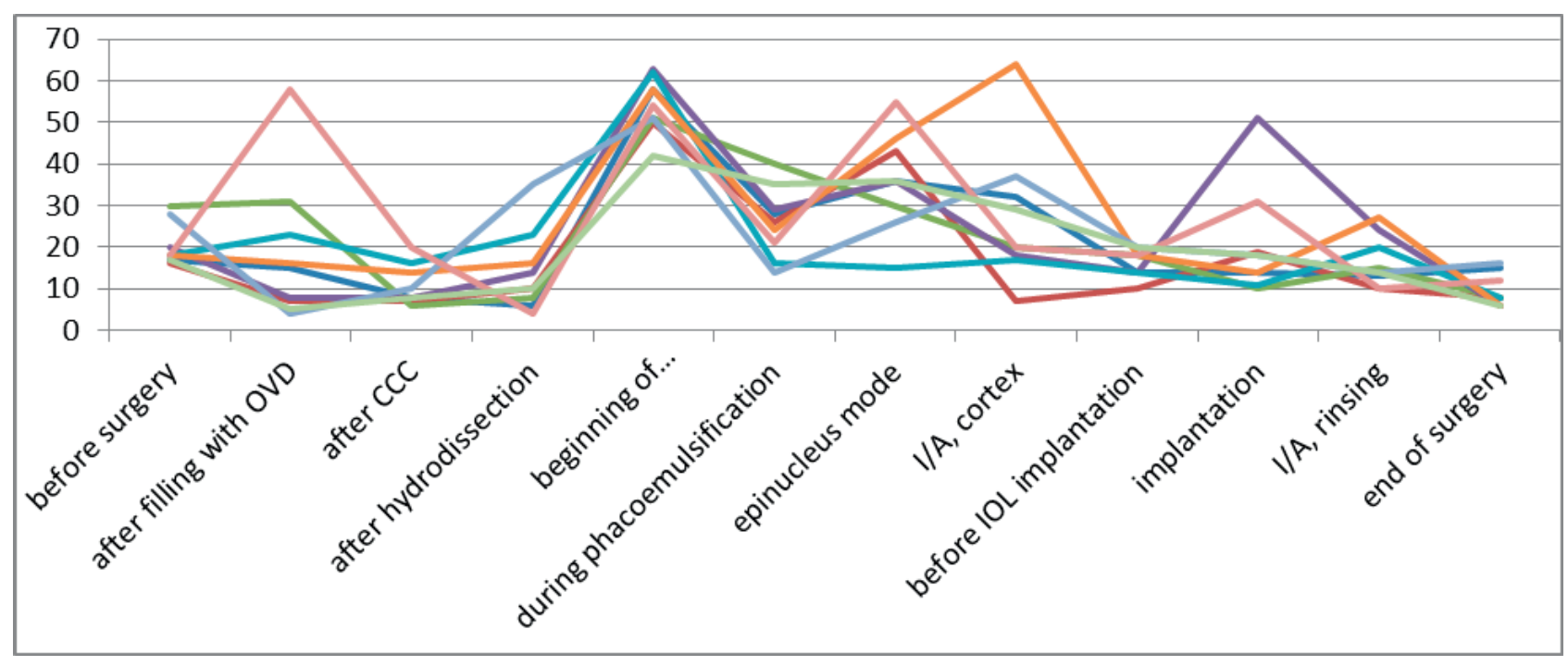

Fig. 1. IOP progression, measured in all ususal steps of phacoemulsification. (OVD - Ophthalmic Viscosurgical Device, CCC continuous curvilinear capsulorhexis, I/A - irrigation/aspiration, IOL - intraocular lens)

in the vitreous body in the cadaver model in the next phases of surgery: during the filling of the anterior chamber with visco-material and during hydrodissection. They revealed that the IOP exceeded $60 \mathrm{mmHg}$ up to $85 \%$ of the time of the phacomelusification procedure ${ }^{2}$.

Rapid fluctuations in IOP in a range of more than 30 $\mathrm{mmHg}$ may lead to disturbance of the intraocular blood flow $^{13}$. Geijer and Bill postulated that retinal ischaemia starts when MOPP is limited to less than about $20 \mathrm{mmHg}$. In our group, the MOPP dropped by more than $20 \mathrm{mmHg}$ in all cases (the values ranged from 21 to 46 , median 36). They also determined that elevated IOP decreased the vascular perfusion and induced a reduction in optic nerve blood supply in monkeys ${ }^{14}$. In healthy eyes, optic nerve head vascular flow was reduced more than $80 \%$ at rapid and significant decreases in the MOPP $\left(\right.$ ref. $\left.^{15}\right)$. In our paper, the IOP was more than baseline in most of the measured parts of surgery, and the ocular perfusion could be severely disturbed briefly, but repeatedly. Modern cataract procedure may run in a few minutes, during which the IOP might be risky high. The ocular hypertension is regularly transient, but the elevated IOP could damage the intraocular vascular flow, and cause a malfunction of the optic nerve or retina. Moreover, there are many patients, who need cataract surgery and at the same time have jeopardized optic nerves, such as advanced glaucoma or other optical neuropathies ${ }^{16}$.

The new devices with active fluidics, where the height of the irrigation bottle is not crucial, are the hope for the future. Active fluidics limits the need for high intraocular tension, while maintaining stability of the anterior chamber $^{17,18}$. At the same time, it also contributes to improving the resulting parameters of the efficacy of phacoemulsification ${ }^{19}$.

\section{CONCLUSION}

In conclusion, both IOP and MOPP, maesured during standard cataract surgery in real patients, varied in all contemporary steps of phocoemulsification procedure. High values of intraoperative IOL may endanger the intraocular perfusion. The short-term fluctuations then may induce impairment of the optic nerve perfusion, as well as retina, and choroid.

Acknowledgment: This study was supported in part by research project Q40/07 (PROGRES) from the Ministry of Health, Prague, Czech Republic.

Author contributions: All co-authors have read the final manuscript within their respective areas of expertise and participated sufficiently in the study to take responsibility for it and accept its conclusions.

Conflict of interest statement: The authors state that there are no conflicts of interest regarding the publication of this article.

\section{REFERENCES}

1. Kelman CD. Phaco-emulsification and aspiration: a new technique of cataract removal-a preliminary report. Am J Ophthalmol 1967;64:2335.

2. Khng C, Packer M, Fine IH, Hoffman RS, Moreira FB. Intraocular pressure during phacoemulsification. J Cataract Refract Surg 2006;32:301-8.

3. Patterson SW, Starling EH. On the mechanical factors which determine the output of the ventricles. J Physiol 1914;48:357-79.

4. Glucksberg MR, Dunn R. Direct measurement of retinal microvascular pressures in the live, anesthetized cat. Microvascular Research 1993;45:158-65.

5. Kiel JW. The Ocular circulation. San Rafael (CA): Morgan \& Claypool Life Sciences; 2010. Chap 4.

6. Sehi M, Flanagan JG, Zeng L, Cook RJ, Trope GE. Relative Change in Diurnal Mean Ocular Perfusion Pressure: A Risk Factor for the Diagnosis of Primary Open-Angle Glaucoma. Invest Ophthalmol Vis Sci 2005;46(2):561-7. 
7. Hayreh SS. Blood flow in the optic nerve head and factors that may influence it. Prog Retin Eye Res 2001;20:595-624.

8. Zhao Y, Li X, Tao A, Wang J, Lu F. Intraocular pressure and calculated diastolic ocular perfusion pressure during three simulated steps of phacoemulsification in vivo. Invest Ophthalmol Vis Sci 2009;50:292731.

9. Findl O, Strenn K, Wolzt M, Menapace R, Vass C, Eichler HG, Schmetterer L. Effects of changes in intraocular pressure on human ocular haemodynamics. Curr Eye Res 1997;16:1024-29.

10. Quigley HA, McKinnon SJ, Zack DJ, Pease ME, Kerrigan-Baumrind LA, Kerrigan DF, Mitchell RS. Retrograde axonal transport of BDNF in retinal ganglion cells is blocked by acute IOP elevation in rats. Invest Ophthalmol Vis Sci 2000;41:3460-6.

11. McCulley TJ, Lam BL, Feuer WJ. A comparison of risk factors for postoperative and spontaneous nonarteritic anterior ischemic optic neuropathy. J Neuroophthalmol 2005;25:22-4.

12. Sharma S, Tun TA, Baskaran M, Atalay E, Thakku SG, Liang Z, Milea D, Strouthidis NG, Aung T, Girard MJ. Effect of acute intraocular pressure elevation on the minimum rim width in normal, ocular hypertensive and glaucoma eyes. Br J Ophthalmol 2018;102:131-5.

13. MoorheadL C, Gardner TW, Lambert HM, O'Malley RE, Willis
AW, Meharg LS, Moorhead WD. Dynamic intraocular pressure measurements during vitrectomy. Arch Ophthalmol 2005;123:1514-23.

14. Geijer C, Bill A. Effects of raised intraocular pressure on retinal, prelaminar, laminar, and retrolaminar optic nerve blood flow in monkeys. Invest Ophthalmol Vis Sci 1979;18:1030-42.

15. Riva CE, Hero M, Titze P, Petrig B. Autoregulation of human optic nerve head blood flow in response to acute changes in ocular perfusion pressure. Graefes Arch Clin Exp Ophthalmol 1997;235:618-26.

16. Lam BL, Jabaly-Habib H, Al-Sheikh N, Pezda M, Guirgis MF, Feuer WJ, McCulley TJ. Risk of non-arteritic anterior ischaemic optic neuropathy (NAION) after cataract extraction in the fellow eye of patients with prior unilateral NAION. Br J Ophthalmol 2007;91:585-7.

17. Nicoli CM, Dimalanta R, Miller KM. Experimental anterior chamber maintenance in active versus passive phacoemulsification fluidics systems. J Cataract Refract Surg 2016;42:157-62.

18. Solomon KD, Lorente R, Fanney D, Cionni RJ. Clinical study using a new phacoemulsification system with surgical intraocular pressure control. J Cataract Refract Surg 2016;42:542-9.

19. Malik PK, Dewan T, Patidar AK, Sain E. Effect of IOP based infusion system with and without balanced phaco tip on cumulative dissipated energy and estimated fluid usage in comparison to gravity fed infusion in torsional phacoemulsification. Eye Vis 2017;17:4-22. 